\title{
The effect of hip abductor fatigue on static balance and gait parameters
}

\author{
Wonjeong Hwang ${ }^{a}$, Jun Ha Jang ${ }^{\mathrm{b}}$, Minjin Huh ${ }^{\mathrm{b}}$, Yeon Ju Kim ${ }^{\mathrm{b}}$, Sang Won Kim ${ }^{\mathrm{b}}$, In Ui Hong ${ }^{\mathrm{b}}$, Mi Young Lee \\ ${ }^{a}$ Department of Physical Therapy, The Graduate School, Sahmyook University, Seoul, Republic of Korea \\ ${ }^{\mathrm{b}}$ Department of Physical Therapy, College of Health and Welfare, Sahmyook University, Seoul, Republic of Korea
}

\begin{abstract}
Objective: Hip abductors play a role in providing stability and movement to the lower limbs. The purpose of this study was to examine the effects of hip abductor fatigue on static balance and gait in the general population.

Design: One group pre-test post-test design.

Methods: Thirteen university students in their twenties volunteered for the study and had underwent a functional assessment. To induce fatigue, the subjects were instructed to raise their dominant lower extremity up against a load of $50 \%$ of 1 repetition maximum while producing hip abduction in a side-lying position. Subjects were instructed to maintain an abduction speed of 30 repetitions per minute to induce fatigue. Muscle fatigue was considered to be established when subjects were unable to perform hip abduction three consecutive times along with the metronome. A post-test of balance and gait was performed immediately in order to prevent fatigue recovery. The center of pressure (COP) distance area was measured using the Zebris FDM-S Multifunction Force measuring plate. Gait performance was analyzed using the GAITRite.
\end{abstract}

Results: The COP distance was increased after fatigue was induced. There was a significant increase in the standard deviation of the medio-lateral and antero-posteror distance $(p<0.05)$. Although there was no significant difference in gait parameters, there was a significant decrease in single support time after fatigue was induced $(p<0.05)$.

Conclusions: There was an increase in static balance instability and a significant decrease in single support time during gait due to hip abductor muscle fatigue.

Key Words: Fatigue, Gait, Postural balance

\section{Introduction}

Hip abductor muscles play a role in providing a connection between the pelvis and the lower limbs and producing stability and lower limb control. Not only is there a relationship between hip abductor weakness and dysfunction, but also femoroacetabular impingement [1], patellofemoral pain [2], and low back pain [3]. One study reported that persons with hip abductor weakness also experienced ankle sprains [4].

Hip abductor muscles have an important function in preventing of a pelvic drop of the opposite side during a one-legged stance. Hip abductor muscle weakness produces a drop or oblique appearance of the pelvis, and in order to maintain stability, leaning of the ipsilateral trunk can be seen for compensation [5]. The gluteus medius muscle on the lateral side provides lateral stability but also has an important function in maintaining the center of mass (COM) during the single limb support phase of the gait cycle [6]. During the performance of a closed kinetic chain exercise, the femur controls for internal rotation, and plays an important role in producing stabilization of the hip [7]. If the function of the gluteus medius is not appropriate, a complete hip abduction movement cannot occur, and consequently leads to poor postural control and hip external rotation [8]. The gluteus medius muscle plays a role in producing pelvic stability and

Received: 16 February, 2016 Revised: 18 March, 2016 Accepted: 18 March, 2016

Corresponding author: Mi Young Lee

Department of Physical Therapy, College of Health and Welfare, Sahmyook University, 815 Hwarang-ro, Nowon-gu, Seoul 01795, Republic of Korea Tel: 82-2-3399-1638 Fax: 82-2-3399-1639 E-mail: mylee@syu.ac.kr

(c) This is an Open-Access article distributed under the terms of the Creative Commons Attribution Non-Commercial License (http://creativecommons.org/licens es/by-nc/4.0) which permits unrestricted non-commercial use, distribution, and reproduction in any medium, provided the original work is properly cited.

Copyright $@ 2016$ Korean Academy of Physical Therapy Rehabilitation Science 
femoral motion control [9].

Muscle fatigue reduces the ability to produce force within the neuromuscular system [10], and is defined as a disability in the production of maximum force [11]. Muscle fatigue corrupts the muscle spindles [12], joint position sense [13], and similar structures. Muscle fatigue produces changes in somatosensory input and results in defective postural control [14].

As already known, damage caused by muscle fatigue includes instability and injury during exercise performance [15]. In addition, one can experience these injuries during daily life activities. Hip abductor muscle fatigue has an effect on hip joint position sense and gait control within healthy elderly people [16]. Local muscle fatigue leads to poor postural control, and furthermore, fatigue of the proximal muscles produce an even greater negative impact on balance ability compared to fatigue of the distal muscles [17].

Fatigue is defined as decreased muscle strength after repeated muscle contractions [18-20]. Fatigue is also considered one of the factors for balance injury $[19,20]$. The gluteus medius muscle plays a large role with balance during one-legged standing. Although studies on fatigue have been performed in the athletic population, studies that have been conducted in the non-athletic population are lacking.

This study was conducted to examine the effects of hip abductor fatigue on static balance and gait parameters in the non-athletic population for postural control as well as the significance of the role of proximal lower extremity muscles on gait.

\section{Methods}

\section{Subjects}

Thirteen healthy university students in their twenties have agreed to volunteer after being informed of the purpose of

Table 1. Characteristics of participants

$(\mathrm{N}=13)$

\begin{tabular}{lc}
\hline \multicolumn{1}{c}{ Variable } & Value \\
\hline Sex $($ male/female $)$ & $6 / 7$ \\
Age $(\mathrm{y})$ & $23.5(1.94)$ \\
Height $(\mathrm{cm})$ & $169.6(8.61)$ \\
Weight $(\mathrm{kg})$ & $62.4(9.21)$ \\
Leg length $(\mathrm{cm})$ & $83.5(6.3)$ \\
RM $(\mathrm{kg})$ & $17.1(9.57)$ \\
BMI $\left(\mathrm{Kg} / \mathrm{cm}^{2}\right)$ & $21.66(1.61)$ \\
\hline
\end{tabular}

Values are presented as number only or mean (SD). RM: repetition maximum, BMI: body mass index. the study and signing an informed consent (Table 1). All subjects were instructed to avoid being involved in extreme sport activities one week prior to the study. The inclusion criteria were as follows: between the ages of 20-29 years, ability to perform a one-legged standing position, and an mini-mental state examination Korean version score of $>24$. The exclusion criteria were as follows: presence of low back pain or neuromuscular injury, disease of the cardiorespiratory system, presence of pain that would make it difficult to participate in the study, consumption of alcohol prior to the study, and inability to appropriately recover from muscle fatigue. Aside from the examiner, an assistant was on standby next to the subject at all times for safety and fall prevention purposes.

\section{Intervention}

In order to induce fatigue onto the gluteus medius muscle of the dominant side, subjects were instructed to lift their dominant lower extremity upwards while the non-dominant lower extremity was placed in 20 degrees of hip and knee flexion on the bottom. A plastic bar was placed as a procedure to promote 30 degrees of hip abduction of the dominant lower extremity (Figure 1) [21]. Subjects were to perform hip abduction without any hip internal or external rotation. A metronome was used to cue subjects to perform hip abduction 30 times per minute.

An external load of $50 \%$ of 1 repetition maximum (RM) was placed. The reliability level of one RM is considered to be high (intraclass correlation coefficient $>0.91$ ) [22]. Fatigue was defined by the subjects' inability to perform 3 consecutive hip abduction movement along with the metronome. The subjects were instructed to perform the post-test requirement within 10 seconds of hip abductor fatigue induction in order to prevent fatigue recovery [23]. The

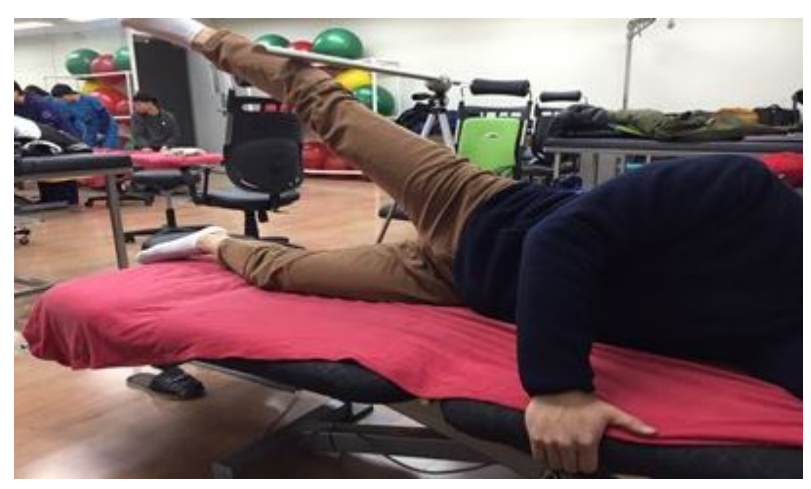

Figure 1. Position inducing fatigue on the gluteus medius. 
post-test examination was performed within a total of 6 minutes.

\section{Outcome measures}

Static balance was considered as the ability to stand bare-footed on the dominant lower extremity with the non-dominant lower extremity in 30 degrees of hip flexion and 45 degrees knee flexion, and gazing in front with bilateral eyes open (Figure 2) [24]. The center of pressure (COP) was measured for 30 seconds using the Zebris FDM-S Multifunction Force measuring plate (Zebris Medical GmbH, Isny im Allgäu, Germany). The system includes a pressure that consists of 2,560 embedded sensors, and the pressure is recorded by each sensor. If the subject's heel of the dominant lower extremity began to descend or if the opposite lower extremity touched the ground, the COP was re-measured. The GAITRite (CIR Systems Inc., Lafayette, NJ, USA) is reported to have a very high reliability was used to assess for the subjects' spatial and temporal parameters while walking $[25,26]$. The GAITRite is a gait analysis system and an electronic gait-analyzing board consisting of a 192 inches $(488 \mathrm{~cm})$ electrical walkway that contains six sensor pads encapsulated in a roll-up carpet to produce an active area that is 24 inches $(61 \mathrm{~cm})$ wide and $0.6 \mathrm{~cm}$ high. The active area is a grid with 48 sensors by 384 sensors, with a distance of $0.5 \mathrm{inch}(1.27 \mathrm{~cm})$ between each sensor, totaling up to 16,128 sensors. A sampling rate of $80 \mathrm{~Hz}$ was used to measure the loading of the subject's feet when the subjects walk on it. A serial interface cable was used to transmit data. Spatiotemporal data collected was processed using the GAITRite GOLD, Version 3.2b software. Subjects were instructed to stand in front of the gait board, and then walk at

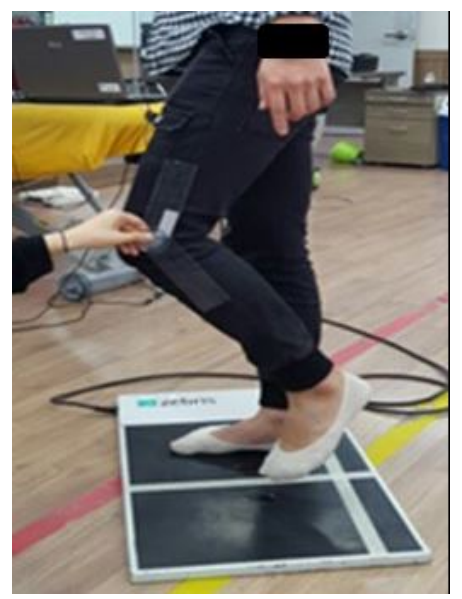

Figure 2. Mesurement of static balance. a self-selected comfortable speed until the end of the board. Subjects were asked to begin walking 1 meter before the GAITRite walkway and up until 1 meter after the walkway at a comfortable speed while the spatial and temporal data were obtained during the middle $5 \mathrm{~m}$ (Figure 3).

Subjects were measured for static balance and gait parameters prior to and after fatigue induction. The static balance parameters assessed were the distance of COP, including medio-lateral, anterior-posteior, the total distance of the COP, as well as the sway variability of the COP, indicating the standard deviation of the medio-lateral and anterio-posterior distance [27]. The gait parameters assessed were velocity, cadence, step length, stride length, single support time and double support time. A total of three measurements were taken and the mean value was obtained.

Due to a small sample size, the Kolmogorov-Smirnov test was used and has shown that there was a significant increase in the SD of the medio-lateral and antero-posteror distance $(p<0.05)$.

\section{Data analysis}

Data was analyzed using the PASW Statistics ver. 18.0 (IBM Co., Armonk, NY, USA). The general characteristics of the subjects are described as the mean and standard deviation (SD) values, and the physical function of the subjects before and after intervention were analyzed using the paired t-test. Data was analyzed with a significance level of $p<0.05$.

\section{Results}

Although the COP distance was greater after fatigue was induced, there was no significant increase. Although there

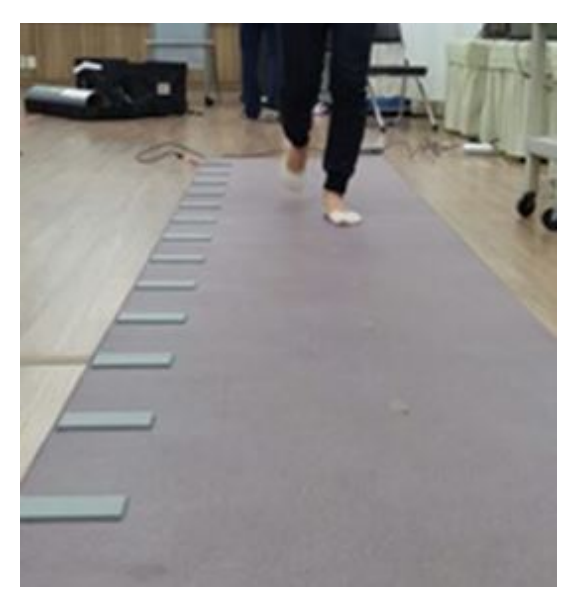

Figure 3. Measurement of gait. 
was no significant improvement in the COP medio-lateral and anterior-posterior distance, there was a significant improvement in the SD values of the COP medio-lateral and antero-posterior distance $(p<0.05)$ (Table 2$)$.

There was no significant difference in gait velocity, cadence, step length, and stride length due to hip abductor fatigue post intervention, however, there was a significant decrease in single support time after intervention $(p<0.05)$ (Table 3).

\section{Discussion}

With hip abductor muscle fatigue, there is a decrease in postural control ability and therefore compensation occurs for neuromuscular adaptation [23]. Fatigue induces changes in the proprioceptive and kinesthetic properties of joints $[28,29]$. Local fatigue within the hip joint brings about postural instability during a single leg task [30]. During the late stance phase, the gluteus medius adjusts for balance by moving the COM towards the medial side [31].

The results of this study show that there was a significant difference in the SD values of the anterior-posterior and medial-lateral excursion of the COP $(p<0.05)$. Bisson et al. [27] reported a significant improvement in the SD of the anterior-posterior COP excursion only when the hip flexors and extensor muscles were fatigued $(p<0.05)$. Since the hip abductor muscles have an affect on postural control in the coronal plane, it would cause variability in the medio-lateral distance. In general, the hip, knee, or ankle strategy is used to compensate for postural instability. Weak hip abductor muscles increase knee abduction $[32,33]$. It is possible to discover weak hip abductor muscles in patients with knee osteoarthritis [34]. In addition, weak hip abduction motion was observed in subjects with chronic unilateral ankle sprain [4]. One study by Kurz et al. [35] mentions that medio-later-

Table 2. Static balance parameters of participants

$(\mathrm{N}=13)$

\begin{tabular}{lccc}
\hline \multicolumn{1}{c}{ Variable } & Pre-test & Post-test & $p$ \\
\hline COP ML (cm) & $15.4(1.34)$ & $14.9(1.34)$ & 0.128 \\
COP AP (cm) & $31.3(6.47)$ & $31.7(6.5)$ & 0.227 \\
COP distance (cm) & $85.7(17.7)$ & $102.3(30.8)$ & 0.067 \\
Standard deviation ML & $0.7(0.15)$ & $0.8(0.26)$ & 0.048 \\
$\quad(\mathrm{~cm})$ & & & \\
Standard deviation AP & $0.4(0.85)$ & $0.5(0.86)$ & 0.024 \\
$\quad(\mathrm{~cm})$ & & & \\
\hline
\end{tabular}

Values are presented as mean (SD).

COP: center of pressure, ML: medio-lateral, AP: antero-posterior. al fluctuation variable is the coefficient of variation (CV) of the medio-lateral COP range. The $\mathrm{CV}$ of the medio-lateral COP was calculated as the SD/mean $\times 100$. Therefore, the $\mathrm{SD}$ of the medial-lateral and anterior-posterior COP infer fluctuation of the COP.

It is important to have a high COM and a small base of support (BOS) when walking forward and perpetually maintaining posture. In particular, it is especially important to maintain postural stability during the mid-stance phase of a single leg stance due to a small BOS. During the stance phase, the COM tries to move outwards due to gravity, however, the gluteus medius, which is a hip abductor, quickly pulls the COM back inwards and thus, providing postural control [31]. This study showed that the single support time was reduced after inducing fatigue onto the gluteus medius muscle, which prevented the muscle from performing its action in completion, and although it was not significant, an increase in cadence was observed. Among the healthy elderly population, when the hip abductor muscle was fatigued, there was no significant improvement in stride time. However, there was a significant increase in stride time $\mathrm{SD}$, and the harmonic ratio was reduced in the medio-lateral direction [16]. When comparing patients during the early stage of total hip arthroplasty with age-matched control subjects, they displayed a slower gait speed, shortened stride length, decreased cadence, and increase trunk lateral displacement. Therefore, total hip arthroplasty patients with weak hip abductor muscles and with limited motion walk using compensation [36]. People who are at risk of falling exhibit a short single support time when walking [37]. Therefore, single support time implies the overall stability [38].

Presence of hip abductor fatigue has shown to cause variation of the COP and affect single support time. It is important to note that hip abductor fatigue is related to the quality of balance and gait patterns and that it should be consid-

Table 3. Gait parameters of participants

$(\mathrm{N}=13)$

\begin{tabular}{lccc}
\hline \multicolumn{1}{c}{ Variable } & Pre-test & Post-test & $p$ \\
\hline Velocity $(\mathrm{cm} / \mathrm{s})$ & $136.84(17.98)$ & $139.88(16.70)$ & 0.249 \\
Cadence (steps/min) & $119.11(7.80)$ & $121.13(8.96)$ & 0.133 \\
Step length (cm) & $68.45(6.27)$ & $69.11(5.59)$ & 0.504 \\
Stride length (cm) & $138.04(12.38)$ & $138.58(11.54)$ & 0.707 \\
Single support time & $0.22(0.02)$ & $0.21(0.02)$ & 0.019 \\
$\quad(\mathrm{~s})$ & & & \\
$\begin{array}{l}\text { Double support time } \\
\text { (s) }\end{array}$ & $0.16(0.04)$ & $0.16(0.03)$ & 0.523 \\
\hline
\end{tabular}

Values are presented as mean (SD). 
ered and taken into account during balance and gait training.

Study limitations included a few number of subjects, and, since the subjects were of young age, there was a possibility for a natural quick recovery of the fatigue. Further studies should include a larger sample size and identify the relationship between fatigue and function according to age group and disease in order to develop a rehabilitation program where fatigue will not interfere with the training process.

\section{Conflict of Interest}

The authors declared no potential conflicts of interest with respect to the authorship and/or publication of this article.

\section{References}

1. Casartelli NC, Maffiuletti NA, Item-Glatthorn JF, Staehli S, Bizzini M, Impellizzeri FM, et al. Hip muscle weakness in patients with symptomatic femoroacetabular impingement. Osteoarthritis Cartilage 2011;19:816-21.

2. Ireland ML, Willson JD, Ballantyne BT, Davis IM. Hip strength in females with and without patellofemoral pain. J Orthop Sports Phys Ther 2003;33:671-6.

3. Tak SJ, Lee YW, Choi WJ, Lee GH. The effects of active release technique on the gluteus medius for pain relief in persons with chronic low back pain. Phys Ther Rehabil Sci 2013;2:27-30.

4. Friel K, McLean N, Myers C, Caceres M. Ipsilateral hip abductor weakness after inversion ankle sprain. J Athl Train 2006;41: 74-8.

5. Magee DJ. Orthopedic physical assessment. 3rd ed. Philadelphia: Saunders; 1997.

6. Pai YC, Rogers MW, Hedman LD, Hanke TA. Alterations in weight-transfer capabilities in adults with hemiparesis. Phys Ther 1994;74:647-57; discussion 657-9.

7. O'Dwyer C, Sainsbury D, O'Sullivan K. Gluteus medius muscle activation during isometric muscle contractions. J Sport Rehabil 2011;20:174-86.

8. Cichanowski HR, Schmitt JS, Johnson RJ, Niemuth PE. Hip strength in collegiate female athletes with patellofemoral pain. Med Sci Sports Exerc 2007;39:1227-32.

9. Fredericson M, Cookingham CL, Chaudhari AM, Dowdell BC, Oestreicher N, Sahrmann SA. Hip abductor weakness in distance runners with iliotibial band syndrome. Clin J Sport Med 2000; 10:169-75.

10. Bigland-Ritchie B, Woods JJ. Changes in muscle contractile properties and neural control during human muscular fatigue. Muscle Nerve 1984;7:691-9.

11. Enoka RM, Stuart DG. Neurobiology of muscle fatigue. J Appl Physiol (1985) 1992;72:1631-48.

12. Balestra C, Duchateau J, Hainaut K. Effects of fatigue on the stretch reflex in a human muscle. Electroencephalogr Clin Neurophysiol 1992;85:46-52.

13. Ribeiro F, Mota J, Oliveira J. Effect of exercise-induced fatigue on position sense of the knee in the elderly. Eur J Appl Physiol 2007;99:379-85.

14. Gribble PA, Hertel J. Effect of lower-extremity muscle fatigue on postural control. Arch Phys Med Rehabil 2004;85:589-92.

15. Salgado E, Ribeiro F, Oliveira J. Joint-position sense is altered by football pre-participation warm-up exercise and match induced fatigue. Knee 2015;22:243-8.

16. Arvin M, Hoozemans MJ, Burger BJ, Rispens SM, Verschueren $\mathrm{SM}$, van Dieën JH, et al. Effects of hip abductor muscle fatigue on gait control and hip position sense in healthy older adults. Gait Posture 2015;42:545-9.

17. Miller PK, Bird AM. Localized muscle fatigue and dynamic balance. Percept Mot Skills 1976;42:135-8.

18. Reimer RC 3rd, Wikstrom EA. Functional fatigue of the hip and ankle musculature cause similar alterations in single leg stance postural control. J Sci Med Sport 2010;13:161-6.

19. Bellew JW, Fenter PC. Control of balance differs after knee or ankle fatigue in older women. Arch Phys Med Rehabil 2006; $87: 1486-9$

20. Letafatkar K, Alizadeh MH, Kordi MR. The effect of exhausting exercise induced muscular fatigue on functional stability. J Social Sci 2009;5:416-22.

21. Patrek MF, Kernozek TW, Willson JD, Wright GA, Doberstein ST. Hip-abductor fatigue and single-leg landing mechanics in women athletes. J Athl Train 2011;46:31-42.

22. Seo DI, Kim E, Fahs CA, Rossow L, Young K, Ferguson SL, et al. Reliability of the one-repetition maximum test based on muscle group and gender. J Sports Sci Med 2012;11:221-5.

23. Lee SP, Powers C. Fatigue of the hip abductors results in increased medial-lateral center of pressure excursion and altered peroneus longus activation during a unipedal landing task. Clin Biomech (Bristol, Avon) 2013;28:524-9.

24. Muehlbauer T, Roth R, Mueller S, Granacher U. Intra and intersession reliability of balance measures during one-leg standing in young adults. J Strength Cond Res 2011;25:2228-34.

25. Bilney B, Morris M, Webster K. Concurrent related validity of the GAITRite walkway system for quantification of the spatial and temporal parameters of gait. Gait Posture 2003;17:68-74.

26. van Uden CJ, Besser MP. Test-retest reliability of temporal and spatial gait characteristics measured with an instrumented walkway system (GAITRite). BMC Musculoskelet Disord 2004;5: 13.

27. Bisson EJ, McEwen D, Lajoie Y, Bilodeau M. Effects of ankle and hip muscle fatigue on postural sway and attentional demands during unipedal stance. Gait Posture 2011;33:83-7.

28. Forestier N, Teasdale N, Nougier V. Alteration of the position sense at the ankle induced by muscular fatigue in humans. Med Sci Sports Exerc 2002;34:117-22.

29. Hiemstra LA, Lo IK, Fowler PJ. Effect of fatigue on knee proprioception: implications for dynamic stabilization. J Orthop Sports Phys Ther 2001;31:598-605.

30. Gribble PA, Hertel J. Effect of hip and ankle muscle fatigue on unipedal postural control. J Electromyogr Kinesiol 2004;14: 641-6.

31. Pandy MG, Lin YC, Kim HJ. Muscle coordination of mediolateral balance in normal walking. J Biomech 2010;43:2055-64.

32. Jacobs CA, Uhl TL, Mattacola CG, Shapiro R, Rayens WS. Hip abductor function and lower extremity landing kinematics: sex 
differences. J Athl Train 2007;42:76-83.

33. Heinert BL, Kernozek TW, Greany JF, Fater DC. Hip abductor weakness and lower extremity kinematics during running. J Sport Rehabil 2008;17:243-56.

34. Lewinson RT, Worobets JT, Stefanyshyn DJ. The relationship between maximal hip abductor strength and resultant loading at the knee during walking. Proc Inst Mech Eng H 2014;228: 1258-63.

35. Kurz I, Berezowski E, Melzer I. Frontal plane instability following rapid voluntary stepping: effects of age and a concurrent cognitive task. J Gerontol A Biol Sci Med Sci 2013;68:1402-8.

36. Nankaku M, Tsuboyama T, Kakinoki R, Kawanabe K, Kanzaki $\mathrm{H}$, Mito Y, et al. Gait analysis of patients in early stages after total hip arthroplasty: effect of lateral trunk displacement on walking efficiency. J Orthop Sci 2007;12:550-4.

37. Bauer CM, Gröger I, Rupprecht R, Marcar VL, Gaßmann KG. Prediction of future falls in a community dwelling older adult population using instrumented balance and gait analysis. $\mathrm{Z}$ Gerontol Geriatr 2015. doi: 10.1007/s00391-015-0885-0. [Epub ahead of print]

38. Jenkins ME, Almeida QJ, Spaulding SJ, van Oostveen RB, Holmes JD, Johnson AM, et al. Plantar cutaneous sensory stimulation improves single-limb support time, and EMG activation patterns among individuals with Parkinson's disease. Parkinsonism Relat Disord 2009;15:697-702. 